\title{
Long-term Facility Resident
}

National Cancer Institute

\section{Source}

National Cancer Institute. Long-term Facility Resident. NCI Thesaurus. Code C102660.

An individual that lives at a healthcare facility that provides rehabilitative, restorative, and/or ongoing skilled nursing care to patients or residents in need of assistance with activities of daily living. 